\title{
Credit-Based Congestion Pricing: A Dallas-Fort Worth Application
}

\author{
Pradeep Gulipalli \\ Consultant \\ Marketing and Planning Systems \\ 201 Jones Road Waltham, MA 02451 \\ Tel: 781-642-6277 \\ pradeepg@gmail.com \\ Kara M. Kockelman \\ (Corresponding Author) \\ Associate Professor \& William J. Murray Jr. Fellow \\ Department of Civil, Architectural \& Environmental Engineering \\ The University of Texas at Austin \\ ECJ 6.9, Austin, Texas 78712, \\ Tel: (512) 471-4379 \\ FAX: (512) 475-8744 \\ Email: kkockelm@mail.utexas.edu
}

The following paper is a pre-print and the final publication can be found in Transport Policy 15 (1):23-32, 2008.

Presented at the 85th Annual Meeting of the Transportation Research Board, January 2006

\begin{abstract}
Previous credit-based congestion pricing (CBCP) studies have surveyed public and expert opinion and examined the traffic and travel-welfare impacts of an Austin, Texas application. This work develops the policy further, predicting traffic impacts, air-quality changes, welfare changes, and system costs for the Dallas-Fort Worth (DFW) region. Joint destination-mode choice models were estimated and applied. The status quo and two marginal cost pricing (MCP) scenarios were simulated for the short-term and long-term, with full feedback of trip costs and times, using the method of successive averages for equilibration. Though significant mode shifts were not predicted total regional vehicle miles traveled and emissions were predicted to fall by roughly $7 \%$ and peak-period freeway speeds were predicted to increase by about $20 \%$. Total travel benefits were quantified as the change in travel demand model logsum terms between the MCP scenarios and the status quo. On average, most of the DFW population (about 95\% of the "credit-eligible" travelers) was predicted to gain from the CBCP policy even after implementation costs were covered for CBCP application on highways. When compared to the case when only freeways are priced, no significant added benefits came from pricing all roads. This study suggests that CBCP can help tackle the problem of congestion in an economically viable, equitable, and efficient fashion.
\end{abstract}

Key Words: Congestion pricing, marginal-cost pricing, travel demand models, traveler welfare, transportation policy 


\section{Introduction}

Building new roads or increasing capacity of existing roads to alleviate congestion is very expensive many times. Also, increasing capacity can allow latent demand to consume much of the travel time savings. Many agree that regions cannot build themselves out of congestion, so demand management is key. Strategies include making the trips shorter and fewer, and spreading them over different modes, routes and time periods. This may be achieved by tolling congested roads, or congestion pricing (CP). Early work in CP includes that by Vickrey (1963), who observed that an effort was underway to differentiate peak and off-peak demand in several markets (e.g., hotels, airlines, and theatres), and something similar for transportation would be useful. Following Vickrey (1963), researchers have extensively discussed the potential of CP for congestion mitigation. However, there are many issues at play including adverse equity impacts. Small (1992) proposed commuter travel allowances, Parry and Bento (2001) recommended income tax reduction, and DeCorla-Souza (2000) suggested toll credits for regular drivers via FAIR (Fast and Intertwined Regular) lanes.

Kockelman and Kalmanje (2004) proposed another version of CP, called credit-based congestion pricing (CBCP), to counter CP's adverse effects. CBCP provides eligible travelers (to be defined) with travel budgets that can then be used to travel on priced roads. Individuals who exhaust their monthly travel budgets must pay out of pocket to keep driving. The budgets are determined by the previous month's net revenues. Kockelman and Kalmanje (2004) polled the Austin, TX public and found that CBCP may compete reasonably well with transportation policy alternatives, particularly once users become more familiar with such policies - and experience tolling firsthand. Kalmanje and Kockelman (2004) predicted Austin trip-based welfare impacts and land value changes under CBCP (travel budgets were assumed to be provided to all the residents with a valid drivers license in this case) and found that this policy benefited most residents, whereas standard CP (without revenue redistribution) benefited relatively few. However, the above analysis does not consider benefits from CP revenue for the standard CP scenario. Gulipalli et al. (2005) interviewed transport economists, toll technology experts, administrators, policy-makers, and commercial users to gauge their opinions and concerns about CBCP. Expert opinion suggested that CBCP is technologically feasible. Based on expert feedback, Gulipalli et al. (2005) concluded that CBCP may be politically viable and provided recommendations for its implementation.

This work studies the impacts of a CBCP policy for the Dallas-Fort Worth (DFW) region. Joint destination-mode (DM) choice models were estimated and applied to the 1999 DFW road network (and 1999 trip productions) for five times of day. Three scenarios were simulated: the status quo (which includes flat tolls on many existing freeway links), marginal cost pricing (MCP) on freeways, and MCP on all roads. The impacts of a CBCP policy in the DFW region were studied in terms of predicted traffic, air-quality, and welfare changes. Kockelman et al. (2005) and Gulipalli (2005) discuss all the above in detail. Due to space limitations, the focus of this paper is on predicted impacts. The following sections summarize the travel demand model (TDM) estimation and application procedures, predicted traffic impacts in terms of change in vehicle miles traveled (VMT), mode shares, congestion levels, and speeds and air-quality impacts. This is followed by a discussion of revenues, costs, some "typical" commute tolls, and travel budget estimates. The welfare changes for various demographic groups are also discussed. Limitations of this work and opportunities for enhancements are described before concluding the paper. 


\section{Joint Destination-Mode Choice Model Estimation}

Joint DM choice models predict the trip-end (attraction zone) choice of an individual traveler and also his/her travel mode. Various zonal attraction and demographic variables were used to model choice of 4874 destination zones and 4 modes for 3 trip purposes based on 32,799 trips in the 1996 DFW household survey dataset and Dallas Area Rapid Transit on-board survey dataset as provided by the North Central Texas Council of Governments (NCTCOG). The 4 modes include drive alone (DA), shared ride (SR), transit, and walk/bike (WB), and the 3 trip purposes are home-based work (HBW), home-based non-work (HBNW), and non-home-based (NHB). Multinomial logit models with 9 destination alternatives (8 randomly chosen) and a non-linearin-parameters specification was used to model the joint DM choice behavior. The choice set was limited for some observations since all the modes were not available for all origin-destination (OD) pairs. The model estimation procedure was coded in GAUSS matrix programming language.

Land area, population, and total employment were included in the model in a log-linear fashion. 3 income categories and 2 vehicle ownership categories were used. Departure time choice models could not be estimated since there were only peak and off-peak travel times to start with.

The values of travel time (by income group and trip purpose) were constrained in the joint DM choice models since the coefficient on the cost turned out to be positive indicating a negative value of travel time, which is unreasonable. The model structure and the estimation procedure are discussed in greater detail in Gulipalli (2005). These models were applied to the DFW region.

\section{Travel Demand Model Application}

Joint DM choice models were applied to the DFW region to simulate 3 scenarios: the status quo, MCP-on-freeways, and MCP-on-all-roads. The zonal trip productions for each trip purpose were available for six demographic groups based on income category and vehicle ownership. They were split across five time periods (per day) based on percentages observed in the $1996 \mathrm{DFW}$ household survey. The joint DM choice model was used to compute the probabilities of different mode-destination alternatives, which were used to compute the production-attraction (PA) matrices. Trip return rates and average vehicle occupancy information, obtained from the survey, were used to obtain the OD trip tables from the PA matrices.

TransCAD's multi-mode multi-user module using stochastic user equilibrium was used for assigning OD trip tables (weighted) on to the 1999 DFW road network. Different networks were used for SR and non-SR trips. The standard Bureau of Public Roads

(BPR) formulation was used to define volume-delay relationships on the links. The generalized cost expression for the MCP cases was derived from the BPR function. The method of successive averages (MSA) was used to equilibrate the feedback model rather than using direct feedback. MSA OD trip tables were assigned to the network to obtain link flows. MSA travel times and costs were fed back to the joint DM application stage. This process was continued for four feedback loops (or till link flow convergence was reached).

The travel times used for modeling and the travel times obtained from TDM application for status quo were compared and found not to be very different. Short run and long run impacts were predicted. To simulate short run impacts of MCP scenarios, employment locations were constrained (to be the same as those chosen under the status quo). Users were allowed to change 
(choose) destinations for their HBW trips in the long(er) run. The TDM application procedure is discussed in greater detail in Gulipalli (2005).

Simulating MCP on some (or all) links is expected to affect traveler choices of modes, destinations, and routes (traveler choice of trip departure time cannot be captured in these models). The negative coefficient on the natural log of generalized cost in the DM choice models indicates that travelers tend to prefer destinations and modes that have a lower generalized cost (travel time and cost). Thus for an MCP scenario travelers can be expected to try to avoid choices involving higher travel times and/or choices where they have to pay higher tolls (i.e. they might be expected to take the less congested routes and/or choose destinations with lower generalized cost and/or shift from DA to other modes). The extent to which travelers change their travel patterns also depends on their income and vehicle availability, which is captured by the models. The predicted traffic impacts are discussed next.

\section{Traffic Impacts}

NCTCOG provided the 1999 DFW roadway network used in this analysis. The DFW road network has 26,748 lane miles and is divided into 22,187 links. 14 percent of the total lane miles are freeways (which are priced in the MCP-on-freeways scenarios) and 14.6 percent are principal arterials. Free-flow speeds assumed for each link are simply 1.1 times the speed limit on those links or $75 \mathrm{mph}$, whichever is lower (where speed limits are primarily defined by facility type).

\section{Vehicle Miles Traveled and Vehicle Hours Traveled}

Link flows and travel times obtained from TDM application suggest that the total system VMT for the both MCP scenarios (MCP-on-freeways and MCP-on-all-roads) will fall by about 7 percent to 8 percent in the long run, when compared to the status quo. In the short run, VMT for the MCP-on-freeways scenario is predicted to fall by 7 percent and by about 6 percent for the MCP-on-all-roads scenario. This is expected since travelers are likely to choose nearer destinations and/or shift from DA to other modes. For example, the average trip length is predicted to decrease from 9.63 to 9.09 miles (5.6\% reduction) for the MCP-on-freeways scenario in the short run. Freeway VMT is predicted to fall by over $12 \%$ for both the MCP scenarios (in the short and long runs), as travelers avoid MCP tolls. In the MCP-on-freeways scenario, VMT on principal arterials (not including freeways) is predicted to fall (approx. -4\%) in the short run, but rise slightly (approx. $+2 \%$ ) in the long run. In the short run, flows on principal arterial links that serve as feeder routes to the freeways are predicted to fall, while flows on those serving as alternatives to the freeways are predicted to rise. The overall result is a decrease in principal arterial VMT in the short run. However, in the longer run (when the employment locations are flexible), users chose their employment locations (work trip destinations) such that the freeways are used less and the arterials used more than in the status quo.

In the MCP-on-all-roads scenario principal arterial VMT is predicted to fall by about $2 \%$ in the short run and by about $5 \%$ in the long(er) run. This suggests that travelers are likely to try and avoid the MCP tolls on all roads (and are able to do it better in the long run by choosing more appropriate work destinations). Figure 1 shows the predicted distribution of daily VMT across facility types in the short run. Travel can also be measured in terms of total travel time or VHT. VHT is predicted to fall more in the long run as work-trip destinations lie closer to homes. Freeway VHT fell by about 19\% in the short run and 21\% in the longer run. As expected, this 
difference was higher for the peak-periods than for the off-peak periods. Predicted mode shifts for the MCP scenarios are discussed next.

\section{Mode Shifts}

Interestingly, the models do not suggest any significant mode shifts for the MCP scenarios. In the short run, MCP-on-freeways saw a slight decrease in DA trips (51.4\% to 50.3\%) and a slight increase in SR trips (43.3\% to 43.6\%) and non-auto trips (5.3\% to 6.1\%). The mode shifts for MCP-on-all-roads were not very different from MCP-on-freeways scenario. Very similar shifts are predicted in the long run also. As expected, the mode shift in the peak-periods was more than that in the off-peak periods since travelers face more MCP tolls in the peak periods. The predicted mode and VMT differences across scenarios indicate that travelers prefer changing destinations and routes rather than changing modes. This suggests that a MCP policy may not cause a significant shift to transit (about 15\% for the MCP-on-freeways case). However, if transit improvements were made an integral part of the pricing strategy, higher mode shifts could be expected, suggesting implications for uses of MCP revenues. Next is a discussion on predicted change in congestion levels for the MCP scenarios, in terms of V/C ratios.

\section{VMT vs. Volume-to-Capacity Ratios and Average Speeds}

To discuss how congestion abates, VMT was split into four categories based on the V/C thresholds of $0.5,0.75,1.00$ and 1.50. A standard BPR specification ( $\alpha=0.15$ and $\beta=4$ ), suggests that speeds at these four points are 1 percent, 4.5 percent, 13 percent, and 43 percent less than the free-flow speeds. Travel at different congestion levels was measured in terms of a VMT percentage at those different V/C ratios.

The models clearly suggest less congested travel for both MCP scenarios, as expected. In the short run for the MCP-on-freeways scenario, VMT at V/C ratios between 1.0 and 1.5 is predicted to fall by about 65\% and VMT at V/C ratios greater than 1.5 is predicted to virtually disappear. (Recall that higher $\mathrm{V} / \mathrm{C}$ ratios will result in much higher travel delays per marginal traveler, and thus much higher congestion tolls.) In the long run, however, VMT at both the above mentioned $\mathrm{V} / \mathrm{C}$ levels is predicted to fall by about $73 \%$.

For MCP-on-all-roads the predicted reduction in VMT for the two top V/C categories is 65\% and $99.3 \%$, respectively, in the short run, and $81 \%$ and $99.7 \%$, respectively, in the long run.

Correspondingly, increases in VMT at lower V/C levels $(<1.0)$ for both MCP scenarios suggest shifts from congested to less congested routes. The increase in VMT at lower V/C levels $(<1.0)$ is higher in the long run compared to the short run, indicating better road space rationing in the long run. It is important to note that decrease in VMT do not indicate simply route shifts, but also indicates shifts in destinations and modes. Figure 2 shows the percentage of travel at different $\mathrm{V} / \mathrm{C}$ levels for the short run. The reduction in congested travel is most pronounced during the peak-periods. The daily average speed (total VMT divided by VHT) for the status quo was predicted to be $45.9 \mathrm{mph}$. This does not change, much across scenarios, rising by about $2 \mathrm{mph}$ for the MCP scenarios.

The traffic impacts discussed in the above sections also translate into air-quality impacts. The emissions for various pollutants and particulate matter were estimated for the status quo and the MCP scenarios using MOBILE6. This is discussed in the following section.

\section{Air-Quality Impacts}


The Environmental Protection Agency (EPA) has established threshold concentrations for various pollutants. These are known as the National Ambient Air Quality Standards, and regions not meeting these standards are designated as non-attainment areas. DFW is a serious nonattainment zone for ozone, requiring careful planning and thoughtful consideration of various potential transportation control measures. This study explored the air-quality impacts of marginal cost pricing (MCP) in the DFW region, in terms of on-road emissions. MOBILE6 estimates of on-road mobile source gaseous emissions and particulate matter were computed for each link, and aggregated over all links and times of the day. Pollutant estimates decreased by 5 to $7 \%$, almost in proportion to VMT for the two MCP scenarios. This is reassuring but is unlikely to be of sufficient practically significance to achieve conformance with air quality standards.

\section{Cost, Revenue, and Budget Estimates}

Estimates of initial investment and recurring costs are required to predict net revenues of a CBCP policy and potential travel budgets for those who qualify. Here, initial investment costs for roadside devices and other technology are based on USDoT (2000a and 2000b) values. The operations and management (O\&M) costs are based on per-lane-mile expenses of various electronic toll collection (ETC) projects. To assume that all freeways would be priced is conservative, since not all freeways are congested. DFW has 594 centerline miles (USDoT, 2000c) (about 3700 lane miles) of freeways. TDM results for the status quo suggest that about $60 \%$ of these are "congested" (V/C $>0.75$ ). The following analysis assumes that $70 \%$ of the DFW freeway network (415 centerline miles and 2600 lane-miles) will be instrumental to permit MCP.

\section{Initial Costs}

Two USDoT reports (USDoT 2000a and 2000b) give a range of costs for toll plaza and toll administration equipment. These were used here to estimate total initial costs. Assuming one toll plaza every 3 centerline miles, as suggested by toll technology experts (Gulipalli et al, 2005), requires around 140 toll plazas. Since only one gantry structure is assumed for all lanes at any point, the higher USDoT estimate is used for mainline structures (see Table 1). Since there are multiple lanes at each plaza, 700 electronic toll readers are required. This assumes one reader per lane for an average of 5 lanes per site, (which is more than the actual average of about 4.2 lanes (both directions) - and thus is felt to be conservative). Around 350 high-speed cameras (each costing $\$ 7,500$ ) would be required (one for every two lanes, to permit violation detection and facilitate policy enforcement [USDoTa, 2000]).

The initial cost is estimated to be $\$ 48.3$ million (Table 1 ), which amounts to a fixed cost of about $\$ 11$ per DFW resident. Transponders represent 65 percent of these initial costs and could very well be covered by user deposits/purchases. Moreover, toll technology already exists in several DFW localities, many drivers already use transponders regularly, and flat-rate tolling may be needed in several corridors, thus moderating costs that can be attributed solely to a CBCP policy.

\section{Recurring Costs}

Operating expenses for the NTTA (NTTA, 2003), New Jersey Turnpike Authority (NJTA, 2003), and San Joaquin Hills Transportation Corridor Agency (SJHTCA, 2003) were used to arrive at system costs of a DFW ETC application. Gulipalli et al (2005) estimated per-lane-mile expenses for each of these systems to fall between $\$ 80,000$ and $\$ 110,000$. CBCP operating expenses per lane-mile are thus estimated to be $\$ 100,000$ per year, or a total of $\$ 260$ million for 
the DFW region's freeway system annually. This corresponds to \$54 per DFW resident annually. In comparison, DFW residents are estimated to experience an average annual congestion cost of \$564 (per resident), which includes delay and fuel costs on all congested roadways (Schrank and Lomax, 2003). 78\% of the congested (V/C > 0.75) VMT is estimated to occur on the freeways, so $78 \%$ of the congested costs (or $\$ 440$ per resident) may be attributed to freeways. The total cost per resident obtained by applying a capital recovery factor to the initial cost (at an interest rate of $6 \%$ over a period of 10 years, the lifetime of the ETC system) is about \$55, which seems like a reasonable investment, relative to the magnitude of current congestion-related losses ${ }^{1}$. These cost calculations appear to support the case for CBCP as a worthwhile congestion mitigation strategy in a region like DFW. However, a more detailed analysis of the social benefits from CP, with different revenue uses as mentioned in Gulipalli et al (2005), presumably could provide a better cost-benefit result. Based on the predicted net revenue from MCP tolls, the following section computes travel budgets for a CBCP application.

\section{Tolls and Budgets}

To get a sense of how long-distance peak-period travelers to central locations may be affected, tolls for commuting to the Dallas CBD from various locations were computed. For example, a Plano, TX resident commuting 45 miles (round-trip) during peak periods to the Dallas CBD is predicted to spend $\$ 4.00$ on MCP tolls in the short run (and \$3.00 in the longer term, after other workers adjust their job and/or home locations). Similarly, a 40 mile peak-period round-trip commute from Arlington to the Dallas CBD would cost $\$ 4.00$ in the short run. While these specific toll experiences average about $10 \$$ per mile (or 6 $\$$ per mile in the longer term), the network's average toll per mile on freeways is predicted to be around $3 \mathbb{\$}$ per mile during the peak periods. Of course, it can be much higher (up to $\$ 1.00$ per mile) on the most congested links. The system is expected to become less congested (and tolls reduced) as activity locations more optimally co-locate over time, but more congested (and thus higher toll rates) as new people and jobs enter the region.

Traveler CBCP budgets can be estimated based on a comparison of MCP revenues with system implementation costs (both operating and capital costs). The total daily toll revenues collected for both MCP scenarios was computed based on toll rates (per mile) and link VMTs aggregated over the DFW region and over the five time periods. As an example, MCP on freeways resulted in about \$2.4 million in daily toll revenues in the short run (fixed employment locations), and $\$ 1.6$ million in the longer run. (Of course, in the long run, more residents will join the region and their travel demands are likely to push congestion levels and associated tolls and revenues even higher.) Daily revenues of \$2.4 million suggest monthly revenue of about \$52.8 million (considering revenue from 22 weekdays only and thus ignoring any weekend revenues [when traffic congestion is often lighter]).

Annual operating expenses of \$260 million suggest monthly operating expenses of \$21.7 million. The monthly cost obtained by applying a capital recovery factor to the initial cost is about $\$ 0.55$ million. So, the net monthly revenue from MCP-on-freeways is estimated to be \$30.6 million (when work destinations are held fixed, or about \$13 million when destinations are made

\footnotetext{
${ }^{1}$ At this point, it should be noted that non-recurrent congestion is more difficult to price away than recurrent congestion (due to driver information and expectations), and optimal congestion pricing certainly does not necessarily mean zero congestion. Thus, it is not clear how much of the \$440 estimate of annual freeway congestion losses may be overcome through pricing. This figure simply establishes an order of magnitude for comparison.
} 
flexible). The total number of vehicles in the region is estimated to be around 3 million (see discussion under Table 1). CBCP travel budgets may best be allocated to registered vehicle owners only (see Gulipalli et al, 2005), but additional budget eligibility criteria (based on usage of priced roads or worker status) may be imposed. So, the ultimate number of budgets may well be less than the number of vehicles in the region. If one assumes that the number of budgets is about 70 percent of the number of vehicles, there would be 2.1 million people eligible for a budget. This may seem a conservative estimate. However, the operating costs are also conservative estimates and may be significantly lower (particularly since the application is on such a large scale, unlike the case studies considered). If net revenue were to be allocated uniformly among all the above individuals, each would get a monthly budget of $\$ 14.60$ under this scenario (MCP-on-freeways, in the short-term).

However, CBCP could be designed so that only freeway-using commuters receive travel budgets. There are about 3 million jobs (when summing the number of basic, service, and retail jobs in the NCTCOG database), so 3 million commuters may be expected. Not all use freeways, however, so perhaps only $90 \%$ of these commuters may be considered eligible for a travel budget. In this case, eligible travelers would receive a monthly budget of \$11.30.

The same analysis as above was conducted for the MCP-on-Freeways scenario in the long run (employment locations flexible). Revenue computations indicate daily revenues of \$1.6 million. Further analysis suggests monthly budgets of about \$6 per eligible user, if budget were to be allocated uniformly among 70\% of the vehicle population, or about $\$ 5$ per month, if only freeway commuters were considered.

\section{Traveler Welfare Impacts by Location and Demographic Category}

User preferences for travel modes, destinations, and residential location determine predicted travel benefits from the CBCP policy. The change in consumer surplus ( $\triangle C S$ ) is a holistic measure of travel benefits and was computed for HBW trips as the difference in the probabilityweighted systematic utilities of all DM choices for the two scenarios (the status quo vs. MCP scenarios). The general equation is as follows:

$$
\Delta C S_{\text {in }}^{H B W}=\sum_{j \in C_{j}} \sum_{m \in C_{m, i}} P_{n e w}^{H B W}(i, j, m, n) V_{\text {new }}^{H B W}(i, j, m, n)-\sum_{j \in C_{j}} \sum_{m \in C_{m, i}} P_{\text {old }}^{H B W}(i, j, m, n) V_{\text {old }}^{H B W}(i, j, m, n)
$$

where $V^{H B W}(i, j, m, n)$ is the systematic utility for an individual $n$ residing in zone $i$ and choosing destination $j$ and mode $m$, and $P^{H B W}(i, j, m, n)$ is the corresponding probability (for HBW trips). Subscripts new and old indicate the after (MCP) and before (status quo) scenarios, respectively. $C_{j}$ is the choice set of all destinations, and $C_{m, i}$ is the choice set of available modes for trip production zone $i$.

For HBNW and NHB trips the change in CS was computed as the difference in the logsums of the two scenarios (see equation below):

$$
\Delta C S_{\text {in }}^{H B N W}=\ln \left[\sum_{j \in C_{j}} \sum_{m \in C_{m, i}} \exp \left(V_{\text {new }}^{\text {HBNW }}(i, j, m, n)\right)\right]-\ln \left[\sum_{j \in C_{j}} \sum_{m \in C_{m, i}} \exp \left(V_{\text {old }}^{\text {HBNW }}(i, j, m, n)\right)\right]
$$

The model structure does not result in a constant marginal utility of money $\left(M U_{\$}\right)$. Instead, this value varies across demographic groups and choice alternatives. Probability-weighted average values of $\mathrm{MU}_{\$}$ were computed for all production zones and user groups for the before and after 
scenarios. The welfare change estimates for all production zones were converted into monetary units by dividing by these $\mathrm{MU}_{\$}$. The welfare changes for NHB zones were averaged across all the origin zones to obtain a single value for the region. A weighted average across time periods provides a composite measure of the welfare change for each trip type at every production zone. And an individual's welfare was computed as the number of trips (of each trip type) he/she makes in a day (obtained from the survey) multiplied by the corresponding welfare value. The CBCP budget of 684 per weekday (or \$15 per month) per eligible traveler was added to this value. The spatial distribution of welfare for different user groups for the MCP-on-freeways scenario was obtained. As an example, Figure 3 illustrates distribution of such welfare changes for the medium income group (annual household income of $\$ 30,000$ to $\$ 75,000$ ) with high vehicle ownership (number of vehicles is greater than or equal to household size).

Welfare gains were predicted to be highest for users near the region's CBDs. These net benefits are predicted to fall with distance from these CBDs. Average budget-eligible travelers in all these CBDs and city centers are expected to gain about 40\$ per day under a CBCP policy on freeways. In contrast, average users in north DFW (excluding the Denton and McKinney CBDs), the northwest region (to the immediate west of Carrollton), and south-DFW (between Cleburne and Waxahachie) are predicted to lose most, on the order of about 30\$/day. In these regions, the medium and high income user groups are expected to lose more than the low income user group. The welfare gains are predicted to be slightly larger (and more spread out) for the MCP-on-allroads scenario in comparison to the MCP-on-freeways scenario. However, given the current costs, implementation costs for MCP-on-all-roads are more than the CBCP revenues. The predicted spatial distribution of welfare changes for a CBCP policy (with MCP on freeways) has implications for budget allocations. Eligible users in regions that are prominent losers (northwest and south DFW) could be considered for larger travel budgets. Alternatively, part of the CBCP revenue could be invested in those regions. The results suggest welfare gains to a majority of the users under a CBCP policy. An average DFW resident may gain more than that predicted by the analysis if welfare-maximizing congestion tolls are imposed (rather than charging tolls that equate link-specific delays to a dollar figure, and use a \$10/hour value-of-time assumption). And various user types may benefit more or less (e.g., high VOTT vs. low VOTT travelers).

Interestingly, the welfare distributions for all user groups show that the region's peripheral zones lose while those in the interior are better off. This may largely be simply an "edge effect", due to neglect of travel to zones outside the 9-county region. The TDM effectively requires that people residing and working on these metroplex edges travel longer distances than they probably do. Of course, the edge population is not as constrained as the map (Figure 3) suggests. In reality, these are contiguous regions with many trip-making opportunities just beyond the region and neglected in the TDMs. In this way, the current set-up predicts longer (hence costlier) trips and the CBCP budget is less likely to offset this predicted travel cost increase. However, in reality, the edge population might be making considerably shorter trips and could be quite a bit better off than what is predicted by these welfare computations.

\section{Implications for a CBCP Policy}

Regardless, spatial distribution of welfare changes across different user groups under a CBCP policy has important implications. If a differential budget allocation system is advocated, welfare change predictions can be used to evaluate different allocations. The analysis indicates that location matters. If differential budget allocation is not possible and not all revenue is returned to the users, some revenues could be devoted to regions losing most. This could be used in several 
indirect ways of compensation. In terms of land area, about 50\%-65\% of the 9-county region is predicted to benefit from a CBCP policy (differs by user group). This area has about $95 \%$ of the region's population (and about $97 \%$ of the region's jobs). So, a majority of the budget eligible population experiences travel benefits from the CBCP policy as suggested by the welfare changes. Of course, the models and their application rely on several assumptions. The associated limitations are discussed in the following section.

\section{Assumptions and Limitations}

The analysis assumes that traveler behavior will not change upon receipt of travel budgets. In other words, road tolls will be perceived much like any other expenditure. In actuality, perceived costs may be conditional on the adopted travel budget allocation policy. Moreover, no one knows how non-cashable or other forms of travel budgets will impact traveler behavior. Ideally, such responses could be incorporated into the modeling framework, for more accurate impact assessment.

Another limitation is that departure time choices are fixed across the five time periods. This choice could not be adequately modeled since transit trips in the on-board survey data did not have information regarding time of day. Also, since there were only two travel time and cost matrices (corresponding to peak and off-peak as is typical MPO practice) to start with, departure time modeling was not reasonable or useful. Of course, users are not highly likely to change their departure times (leave earlier or later) across the five rather broad (3+ hour) time periods used in this study, but some shifting will no doubt occur, particularly within the peak periods. A stated preference survey about departure time shifts would be helpful or a transfer of model parameters based on other data sets may be valuable, particularly when paired with dynamic traffic assignment methods. In addition, it was not possible to incorporate all the potential long-term effects of MCP. Such effects may include land use changes, like relocation of households and jobs. Property value changes may also occur, resulting in additional welfare effects.

The welfare computations required many assumptions, and the resulting welfare values are, of course, estimates. Moreover, after controlling for home location and some effects of vehicle ownership and household income, these welfare values are for the region's "average traveler." In reality, there is expected to be wide variation among travel patterns. It would be best for to look at some actual travelers - with different trip needs, VOTTs, and time and cost changes. The TDM's travel behavior predictions are estimates, as are the systematic utility expressions. Moreover, the $\mathrm{MU}_{\mathbb{S}}$ values vary by choice, so a probability-weighted average value of $\mathrm{MU}_{\mathbb{S}}$ had to be used. The welfare computations include a travel budget term (68\$/weekday per eligible traveler), which is somewhat uncertain. It depends on project implementation costs (which were estimated conservatively) and revenue distribution (traveler eligibility was restricted to 70 percent of the worker population).

Also, the tolls charged and route choices are based on a higher VOTT (\$10/hour) than those assumed in the DM choice models (so as to observe greater traffic impacts), which assume VOTTs ranging from $\$ 5$ to $\$ 10 /$ hours (depending on trip and traveler type). This results in higher tolls - and greater congestion relief (and thus traffic impacts). However, since the welfare calculations are based on behavioral models' lower VOTTs, predicted welfare gains are expected to be lower than actual gains. However, not everyone may receive a travel budget. The lack of such a budget may well result in negative impacts for various traveler types. Nevertheless, the population is not as constrained as the map (Figure 3) suggests. In reality, these are contiguous 
regions with many trip-making opportunities just beyond the region neglected in the TDMs. The welfare computations neglect external attraction zones, so the edge population may be quite a bit better off than what is predicted by these computations.

Finally, this analysis uses the standard BPR coefficients (0.15 and 4.00), which are expected to be biased low when using true capacity values. Horowitz (1991) has suggested 0.88 and 9.8 for freeways with a $70 \mathrm{mph}$ speed limit, and 0.56 and 3.6 for freeways with a $50 \mathrm{mph}$ speed limit. Due to this distinction, estimates of MCP tolls, mode shifts, and other travel impacts might as well have been biased low.

\section{Conclusions}

Demand management seems to be the key to congestion alleviation, given the high costs of capacity addition and the presence of significant latent demand in congested regions.

Researchers have suggested different solutions to overcome the adverse equity impacts of CP. Kockelman and Kalmanje (2004) proposed a credit-based congestion pricing (CBCP) policy, which has the potential to allay CP's equity concerns. Kalmanje and Kockelman (2004) studied trip-based welfare impacts and predicted property value changes under a possible CBCP policy for the Austin region. Gulipalli et al (2005) studied expert opinion on CBPC and provided recommendations for the implementation of such a policy. This work explored the short term and long term traffic impacts, welfare changes, and air-quality impacts of a CBCP policy in the DFW metroplex and estimated net-revenues and travel budgets.

Multinomial logit models of destination and mode choice were estimated for three different trip purposes and applied across DFW's 4874 traffic serial zones in 5 times of day. Full feedback of travel times and costs was implemented via MSA equilibration. Three scenarios were simulated: Status quo, MCP-on-freeways, and MCP-on-all-roads in the 22,187 link network with both work trip destinations fixed (short run) and flexible (long run).

VMT for both MCP scenarios was predicted to fall by about 7 percent, indicating that people tend to choose nearer destinations (as suggested by decrease in average trip length) and/or shift from DA to other modes in the presence of pricing. Freeway VMT fell by more than 12 percent for both scenarios (relative to the status quo). The mode shifts were very marginal (<2 percent) in favor of transit and walk/bike modes, indicating that travelers are more likely to change destination and/or routes rather than change their modes. However, this impact might be felt by transit agencies, as the shifts represent a 15 percent increase in transit ridership estimates. A comparison of VMT at different V/C levels suggested dramatic reductions in highly congested travel for MCP scenarios. For MCP-on-freeways, VMT at V/C > 1.5 was predicted to practically disappear in the short run, and fall about 73 percent in the longer run. A corresponding increase in VMT at lower V/C levels was predicted, indicating a shift to relatively uncongested routes. VHT was predicted to fall by 20 percent for the MCP scenarios. Emissions fall by 5 to 7 percent on par with VMT.

Conservative estimates of initial and recurring costs of implementing a CBCP policy along DFW freeways are estimated to be about \$55 per DFW resident, when annualized. When these implementation costs are allocated uniformly across eligible individuals, monthly net revenues are estimated to permit a travel budget of about $\$ 15$ per eligible individual in the short-term and $\$ 6$ in the longer term. The \$15 budget was used to estimate welfare changes (in the short run). 
CBCP policy benefits, as measured by the net welfare estimates, were predicted to be the highest for users near the CBDs, with net benefits predicted to average about 40\$/day. Users in north DFW (excluding the Denton and McKinney CBDs), the northwest regions (to the immediate west of Carrollton), and south DFW (between Cleburne and Waxahachie) were predicted to lose most, losing about 30\$/day. While pre-budget losses are predicted to be less for the MCP-on-allroads scenario, in comparison to the MCP on-freeways scenario, the costs may be significantly higher, resulting in lower net revenues for budget allocation.

The predicted spatial distribution of welfare changes for a CBCP policy has implications for credit distribution. If differential budget allocation is advocated, eligible users in regions that are the less likely to benefit (such as northwest and south DFW) could be considered for larger travel budgets. Alternatively, some portion of CBCP revenues could be invested in those regions. The results of these analyses suggest welfare gains to a majority of the users under a CBCP policy on freeways. Benefits may be greater if tolls are more optimally calculated (recognizing that the entire system is not priced, so MCP tolls are higher than optimal). These results reinforce CBCP's role as a welfare-enhancing congestion-mitigation tool. This study suggests that CBCP can help tackle the problem of congestion in an economically viable, equitable, and efficient fashion. As such, CBCP is a powerful idea with significant potential.

\section{Acknowledgements}

We wish to thank the Texas Department of Transportation for financially supporting this study under research project \#0-4634 and Ms. Kim Limberg for her efforts as the project director. We thank Mr. Ken Cervenka of NCTCOG and other NCTCOG personnel for their input. We thank Ms. Surabhi Gupta for a terrific job on GISDK coding for travel demand model application. Thanks also go to Dr. Sivaramakrishnan Srinivasan and Mr. Sukumar Kalmanje for their inputs.

\section{References}

DeCorla-Souza, Patrick. (2000) "FAIR Lanes: A New Approach to Managing Traffic Congestion,” ITS Quarterly, Vol. VIII, No.2

Gulipalli, P. K. (2005) “Credit-Based Congestion Pricing: Impact Assessment for the DallasForth Worth Region and Policy Recommendations,” Masters Thesis, The University of Texas at Austin.

Gulipalli, P. K., Kalmanje, S., and Kockelman, K. (2005) “Credit-Based Congestion Pricing: Expert Expectations and Guidelines for Application,” Presented at the $84^{\text {th }}$ Annual Meeting of Transportation Research Board, Washington DC.

Horowitz, A. J. (1991) “Delay Volume Relations for Travel Forecasting based on the 1985 Highway Capacity Manual,” Federal Highway Administration, Report FHWA-PD-92-015.

Kockelman, K., Gulipalli, P., Waller, T., Ukkusuri, S., Karoonsoontawong, A. (2005) "Application of Credit-Based Congestion Pricing in Texas: Operational Considerations and Impacts,” Texas Department of Transportation Research Project 0-4036, Report. Center for Transportation Research, The University of Texas at Austin.

Kockelman, K. and Kalmanje, S. (2004) “Credit-Based Congestion Pricing: A Policy Proposal and Public's Response,” Presented at the $83^{\text {rd }}$ Annual Meeting of Transportation Research Board, Washington DC, and forthcoming in Transportation Research A. 
Kalmanje, S. and Kockelman, K. (2004) "Credit-Based Congestion Pricing: Travel, Land Value and Welfare Impacts,” Transportation Research Record 1864: 45-53.

NJTA (2003) "Statement of Revenues and Expenses for the Year Ended December 31, 2003,” First Consolidated Toll Road Annual Report 2003, New Jersey Turnpike Authority.

NTTA (2003) “Financial Statements and Supplementary Data 2003,” North Texas Tollway Authority, Dallas North Tollway System. Accessed from http://www.ntta.org/pub/pub/DNTSPDF.pdf on May 2, 2005.

Parry, I. W. H. and Bento, Q. (2001) "Revenue Recycling and the Welfare Effects of Road Pricing,” Scandinavian Journal of Economics, 103(4): 645-671.

Schrank, D. and Lomax, T. (2003) “The 2003 Urban Mobility Report,” Texas Transportation Institute, The Texas A\&M University.

SJHTCA (2003) "Statement of Revenues, Expenses and Changes in Fund Net Assets (Deficit) for the Year Ended June 30, 2003,” Annual Financial Report 2003, San Joaquin Hill Transportation Corridor Agency.

Small, K. (1992) “Using the Revenues from Congestion Pricing,” Transportation, 19: 359-381. USDoT (2000a) “Unit Costs: Equipment Costs for Toll Plaza (TP),” ITS Benefits and Costs Database, US Department of Transportation. Accessed from http://www.benefitcost.its.dot.gov/its/benecost.nsf/SubsystemCosts?OpenForm\&Subsystem=Tol l+Plaza+(TP) on June 20, 2004.

USDoT (2000b) “Unit Costs: Equipment Costs for Toll Administration (TA),” ITS Benefits and Costs Database, US Department of Transportation. Accessed from http://www.benefitcost.its.dot.gov/its/benecost.nsf/SubsystemCosts?OpenForm\&Subsystem=Tol l+Administration+(TA) on June 20, 2004.

USDoT (2000c) “Urbanized Areas -2000 Selected Characteristics,” Highway Statistics 2000, US Department of Transportation. Accessed from http:/www.fhwa.dot.gov/ohim/hs00/hm72.htm on June 24, 2004.

Vickrey, W. S. (1963) "Pricing in Urban and Suburban Transport," American Economic Review; Papers and Proceedings, 53: 452- 465. 
Table 1: Initial technology cost estimates for a CBCP application on DFW freeways. (All cost estimates are in 2003 US dollars.)

\begin{tabular}{|l|c|c|c|}
\hline One-time investment & $\begin{array}{c}\text { Unit cost } \\
\text { estimate }\end{array}$ & $\begin{array}{l}\text { No. of } \\
\text { Units }\end{array}$ & Total Cost \\
\hline ETC structure & $\$ 15,000$ & 140 & $\$ 12,100,000$ \\
ETC software & 7,500 & 140 & $1,050,000$ \\
ETC readers & 3,500 & 700 & $2,450,000$ \\
High speed cameras & 7,500 & 350 & $2,625,000$ \\
Toll administration hardware & & & \\
(Includes 2 workstations, a & 12,500 & 1 & 12,500 \\
printer, and modem) & & & \\
Toll administration software & & & \\
(Includes COTS software & 60,000 & 1 & $30,000,000$ \\
and database) & 10 & $3,000,000^{* *}$ & \\
Toll tags* & & & $\$ 48,297,500$ \\
\hline Total cost & & & \\
\hline
\end{tabular}

${ }^{*}$ eGo ${ }^{\mathrm{TM}} 2201$ (Transcore, 2002)

** This is the number of vehicles in DFW. The number of households in the year 1999 is $1,808,402.35 \%$ have 1 vehicle, $41.6 \%$ have 2 vehicles, $12.8 \%$ have 3 vehicles, $3.3 \%$ have 4 vehicles, $1 \%$ have 5 or more vehicles (1990 US census). This suggests about 3 million vehicles. 


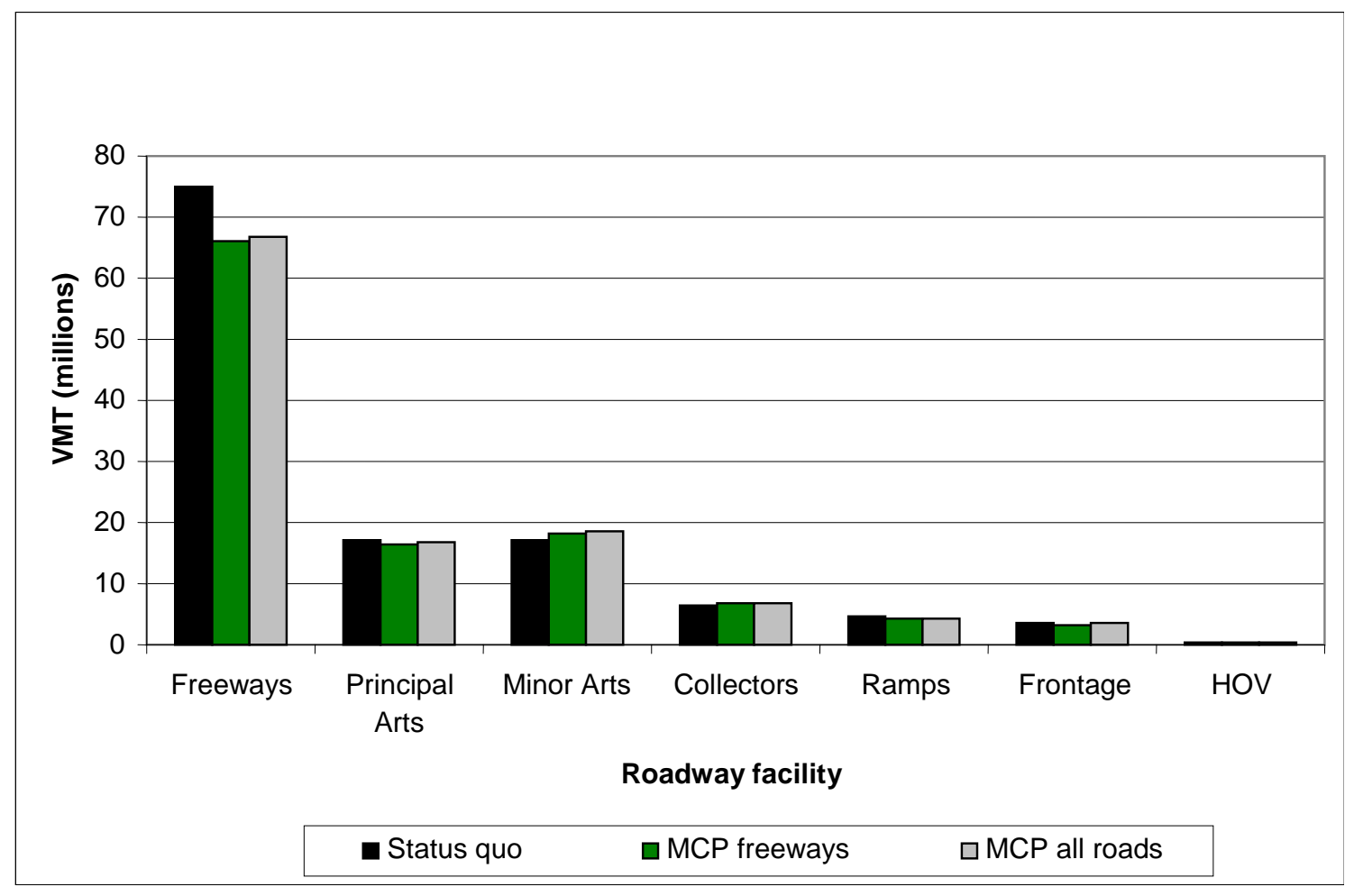

Figure 1: Daily VMT by roadway facility type for different scenarios (Short-term) 


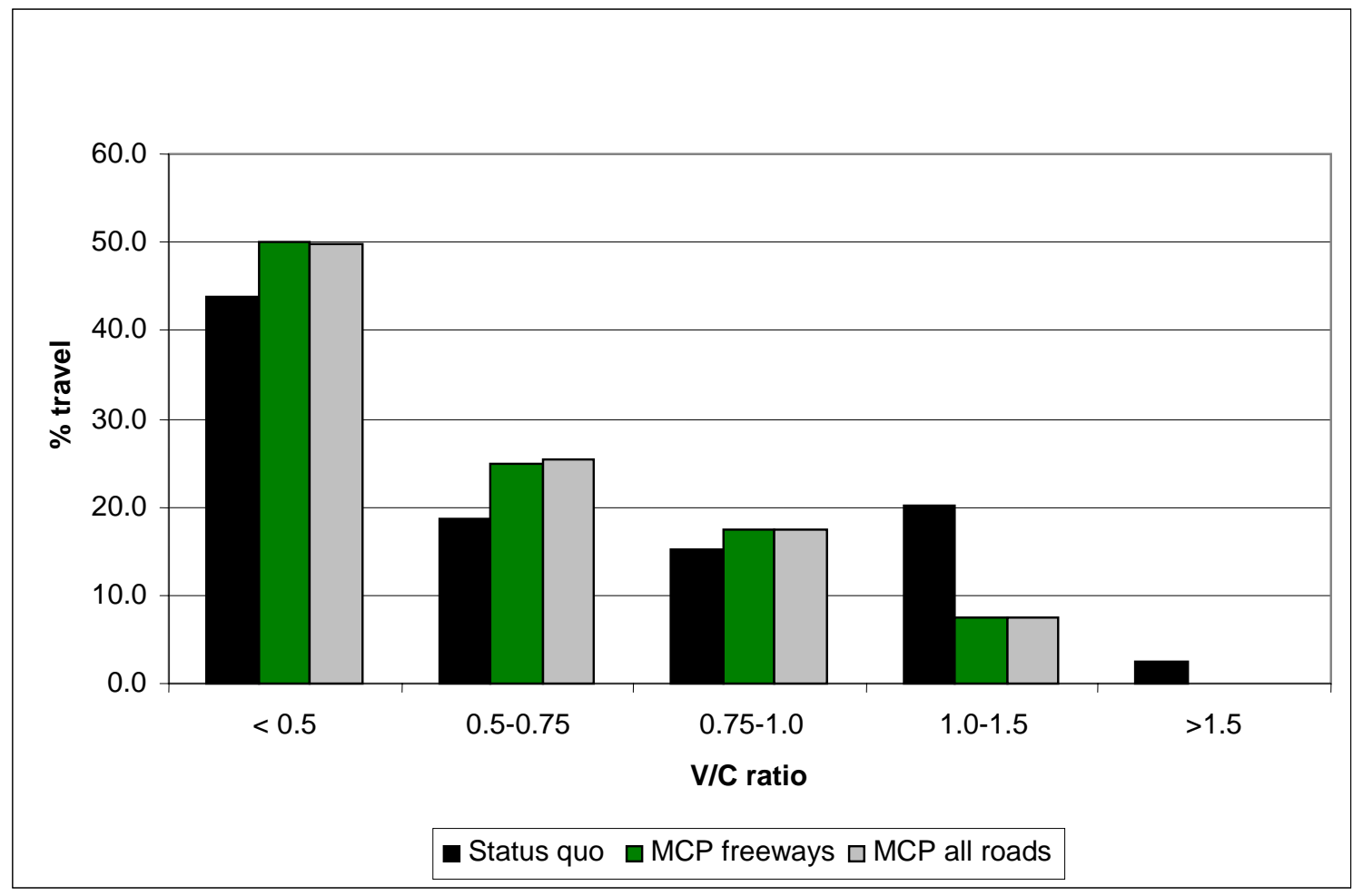

Figure 2: Percentage of daily travel (person VMT) at different V/C levels for different scenarios (Short-term) 


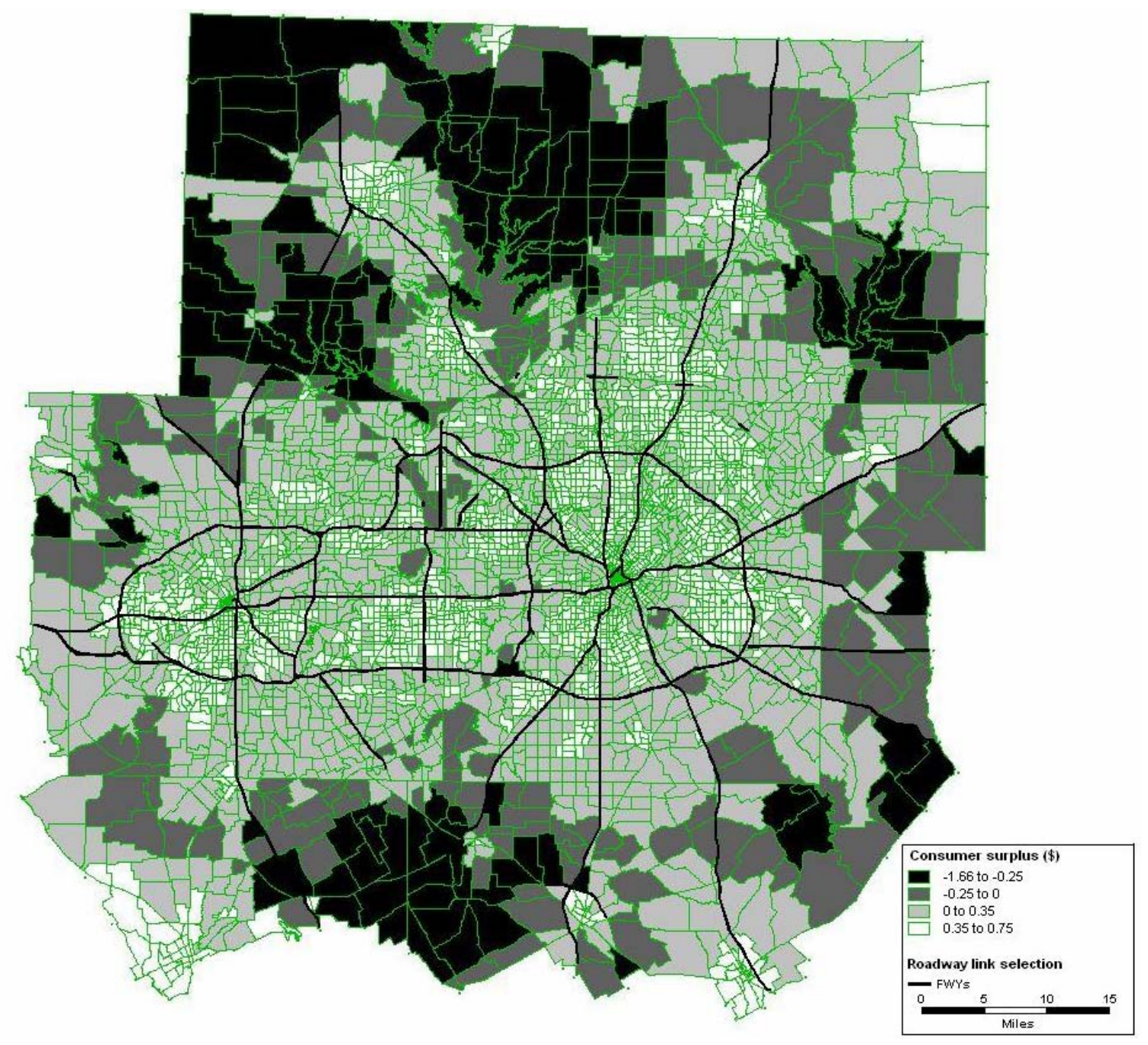

Figure 3: Predicted welfare changes for medium income and high vehicle ownership travelers under a policy of CBCP on freeways (\$ per day) 